\title{
Malocclusion in Children With and Without Cleft Lip - A Case Control Study
}

\author{
Yashila Periyasamy ${ }^{1}$ Vignesh Ravindran ${ }^{1 *}$ and Subhashini VC $^{2}$ \\ 'Department of Pedodontics, Saveetha Dental College and Hospitals, Saveetha Institute \\ of Medical and Technical Sciences, Saveetha University, Chennai 77, India \\ ${ }^{2}$ Department of Public Health Dentistry, Saveetha Dental College and Hospitals, Saveetha \\ Institute of Medical and Technical Sciences, Saveetha University, Chennai 77, India \\ Corresponding author email: vigneshr.sdc@saveetha.com
}

\begin{abstract}
There is a principle agreement that malocclusion is a major health concern as it is the third most common oral disease, next only to dental caries and periodontal disease. As it is a major challenge for even normally abled children to handle these problems, questions arise as to the difference in the extent or severity of manifestation of malocclusion in the oral cavity of patients with cleft lip. The aim of the study was to determine the prevalence of malocclusion in children with and without cleft lip. A total of 89000 cases were reviewed between June 2019 to March 2020 for incidence of malocclusion in individuals with and without cleft lip only. A sample size of 3 case sheets were reviewed for malocclusion in children with cleft lip only. The data was obtained from dental treatment records of a private dental institute. Data was analysed using SPSS software and Mann-Whitney was done. The results showed that children with cleft lip showed higher incidence of malocclusion (100\%) when compared to children without cleft lip (67\%). Higher prevalence of malocclusion was noticed in the case group (children with cleft lip) when compared to the control group (children without cleft lip) $(\mathrm{p}=0.18)$. Within the limitations of the present study, children with cleft lip showed higher incidence of malocclusion than the control group.
\end{abstract}

KEY WORDS: CLEFT LIP; MALOCCLUSION; ORAL HEALTH; PREVALENCE.

\section{INTRODUCTION}

Malocclusion is a problem affecting the teeth where there is misalignment of those teeth in relative to a normal alignment. Some of the most common dental malocclusion includes crowding, overbite, underbite, open bite, crossbite, malocclusion of the anteroposterior plane which are Class II and III, and skeletal malocclusion. These are the most commonly occurring deviations of the teeth from the ideal occlusion. Malocclusion has been identified as the third most common dental health problem, following dental caries and periodontal disease with a global prevalence that varies from 20 to 80 percent. A study conducted in Rajasthan, India reported prevalence rate of 36.42 percent and another in

Biosc Biotech Res Comm P-ISSN: 0974-6455 E-ISSN: 2321-4007

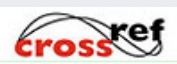

Identifiers and Pagination

Year: 2021 Vol: 14 No (10) Special Issue

Pages: $128-133$

This is an open access article under Creative

Commons License Attribn 4.0 Intl (CC-BY).

DOI: http://dx.doi.org/10.21786/bbrc/14.10.21 the state of Tamil Nadu, India showed a prevalence rate of 15 percent. In this existing study, alteration to the shape of jaw that is also a reason for malocclusion was focused on, in a particular cleft lip case ( Dhar et al., 2007; Mtaya et al., 2009; Shivakumar et al., 2010).

Orofacial clefts or cleft lip and/or palate are opening or splits in the upper lip, roof of the mouth (palate) or both. Orofacial clefts are oral and facial malformations that occur very early in pregnancy, during the development phase inside the uterus. The lip forms between the fourth and seventh weeks of pregnancy. A cleft lip can be on one or both sides of the lip or in the middle of the lip, which occurs very rarely. Children with a cleft lip also can have a cleft palate. They are grouped into unilateral or bilateral and occur when tissues of the face and mouth fail to fuse with each other. The cause is believed to be an interaction of genetic and environmental factors, though in many cases, a definite cause is yet to be established.

Cleft lip and/or palate is a crucial public health problem affecting 1 in every 500 to 1000 births worldwide according to a World Health Organization study conducted back in 2001.
Article Information

Received: $10^{\text {th }}$ Aug 2021

Accepted after revision: $29^{\text {th }}$ Oct 2021 
The number of children born every year with cleft lip and/or palate is 28000 approximately in India alone, amounting up to a significant number of 78 births per day of babies with some form of cleft. Children's with cleft, amongst social and psychological problems, also face physical difficulties in the form of function, feeding, dental problems, speech, and aesthetics. Among these complications, dental problems, in particular malocclusion, is a major drawback. Previous studies, regarding malocclusion in patients with cleft lip and/ or palate reported that they were more prevalent and severe in cleft lip and/or palate patients when compared to noncleft lip and/or palate patients. In a study by Akshay et al., reported that prevalence of Class II and III, a malocclusion along the horizontal plane, was more prevalent in cleft lip and/or palate patients when compared to non-cleft lip and/ or palate patients (Vettore et al., 2011; Gupta et al., 2016; Heliövaara et al., 2021; Kalaskar et al., 2021).

Due to malocclusion, there will be higher chances of dental caries which eventually lead to pulpal involvement, there by leading to treatment such as extractions or rotary endodontics To reduce the incidence of dental caries ,proper oral hygiene measures like proper tooth brushing ,frequent application of topical fluoride will help in reducing dental caries in such patients. (Somasundaram et al., 2015; Gurunathan and Shanmugaavel, 2016; Ravikumar et al., 2017; Subramanyam et al., 2018; Lakshmanan et al., 2020; Govindaraju et al., 2017a; Govindaraju et al., 2017; Govindaraju and Gurunathan, 2017; Jeevanandan, 2017; Jeevanandan and Govindaraju, 2018; Govindaraju and Gurunathan, 2017; Ramakrishnan and Bhurki, 2018).

Previously our team has a rich experience in working on various research projects across multiple disciplines (Gheena and Ezhilarasan, 2019; Ke et al., 2019; Malli et al., 2019; Mehta et al., 2019; Samuel et al., 2019; Varghese et al., 2019; Venu et al., 2019; Vignesh et al., 2019; Jain et al., 2019; Jose et al., 2020; Krishnaswamy et al., 2020; Muthukrishnan et al., 2020; Samuel et al., 2020; Sathish and Karthick, 2020). Now the growing trend in this area motivated us to pursue this project.

This study was aimed to determine the prevalence of malocclusion in children with cleft palate only and to establish if there is a positive association between the patients with cleft palate and occurrence of malocclusion. This knowledge can be used to educate the parents of cleft patients so that they can be better prepared to provide proper care for their children and also to prompt dentists to consider malocclusion as a plausible complication in the future, thus being able to procure a more efficient treatment plan.

\section{MATERIAL AND METHODS}

Study setting for the current retrospective study was a hospital-based University setting. Institute's ethical committee provided the ethical approval for this study (ethical approval number: SDC/SIHEC/2020/DIASDATA/06190320). Consent were obtained from patients/guardians to use treatment records for research purposes at the time of patient entry. 89000 dental case records were collected from the university from June 2019 to March 2020. The inclusion criteria for the current study were 3-17-year-old children with cleft lip, complete intraoral examination data including the case sheet and photographs of the patient. Age and gender matched controls were taken according to the obtained cases in the study group. Incomplete and/or censored dental records and missing photographic evidence of cleft lip and clinical findings were excluded.

A reviewer, a guide and a researcher examined ad reviewed the collected data from case sheets. An additional reviewer cross checked the data. To minimise sampling bias, simple random sampling was done for data collection. The examiner was trained to assess and add data of malocclusion as present or absent for both case and control group by tabulation using excel software and even the type of malocclusion was noted. Data analysis was done using SPSS PC Version 23.0 (IBM;2016) software for statistics. The incidence of malocclusion for both case and control group were compared by Mann-Whitney U Test.

\section{RESULTS AND DISCUSSION}

Study population consisted of 6 children totally, divided equally into case and control group (Figure 1). In the case group, the case sheet of all 3 children were reviewed, in which $2(33.3 \%)$ were males and $1(16.67 \%)$ was a female. In the control group, there were also $2(33.3 \%)$ males and $1(16.67 \%)$ female. The gender distribution in the control group was age and gender matched to the case group (Figure 2). Children in the control group had 2 children with malocclusion, in which, 1 (16.6\% of the total samples) patient had crowding, 1 (16.6\% of the total samples) had scissors-bite, while 1 (16.6\% of the total samples) had normal occlusion. In the case group, all 3 children $(50 \%$ of the total samples) had scissor-bite (Figure 3). Case group had a higher prevalence of malocclusion when compared to the control group, which was not statistically significant $(\mathrm{p}$-value $=0.18)$.

Figure 1: The graph bar shows case distribution in the case group and the control group. (X-axis represents presence or absence of cleft lip; Y-axis represents number of cases) Notice the equal distribution of cases for both the case group and control group.

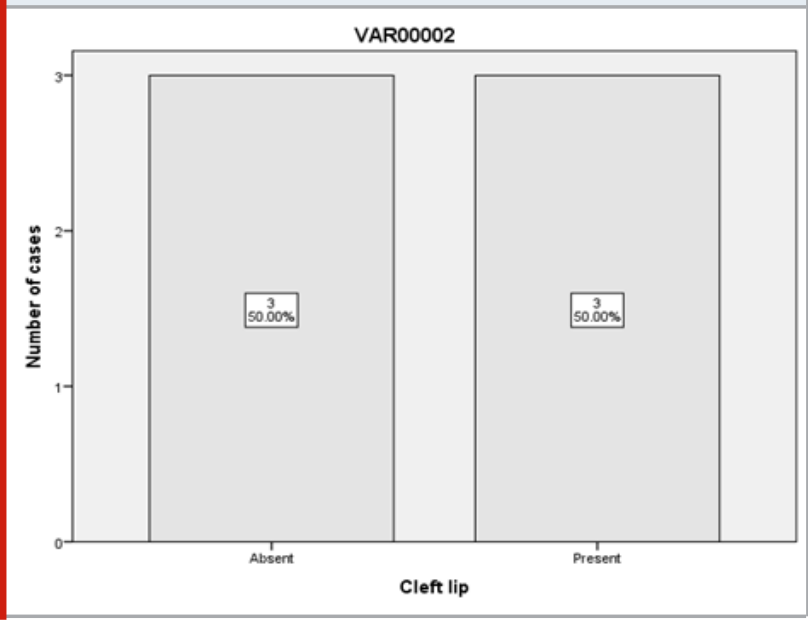


Figure 2: Bar graph representing gender distribution in the case group and the control group. (Y-axis represents number of cases; $\mathrm{X}$-axis represents presence or absence of cleft lip; lighter grey represents males and darker grey represents females) Notice the equal distribution of cases based on gender in both the case and control groups.

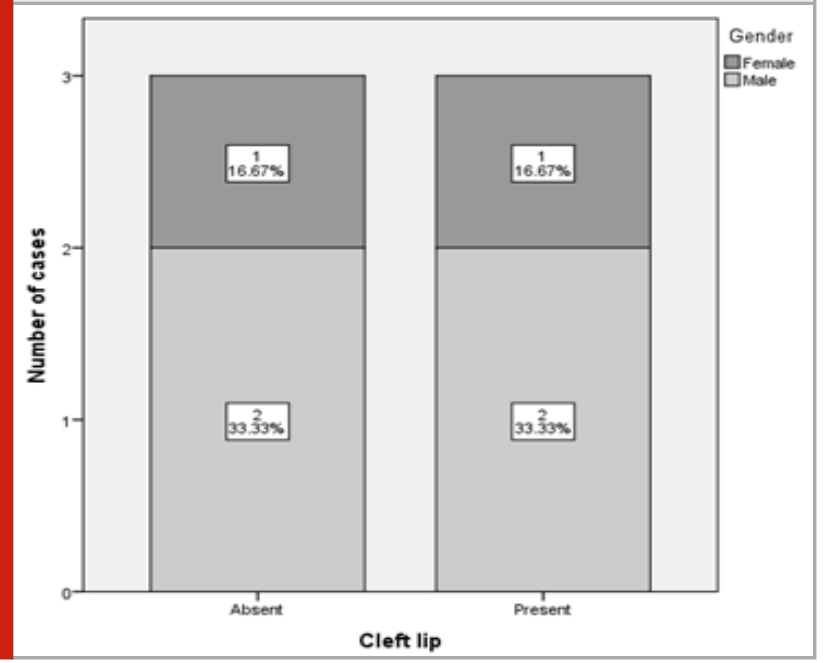

Figure 2: Bar graph shows the comparison of type of malocclusion in the case group and the control group. (Y-axis represents a number of cases; $\mathrm{X}$-axis represents the presence or absence of cleft lip; Blue color represents absence of malocclusion; green color represents cross bite; yellow color represents crowding; violet color represents spacing). Children in the control group had two children with malocclusion, in which one patient had crowding, one had crossbite, while one child did not have malocclusion. In the case group, all three children had crossbite. Higher prevalence of malocclusion was noticed in the case group when compared to the control group. (Mann-Whitney $\mathrm{U}$-Test; p-value $=0.18$ - not significant)

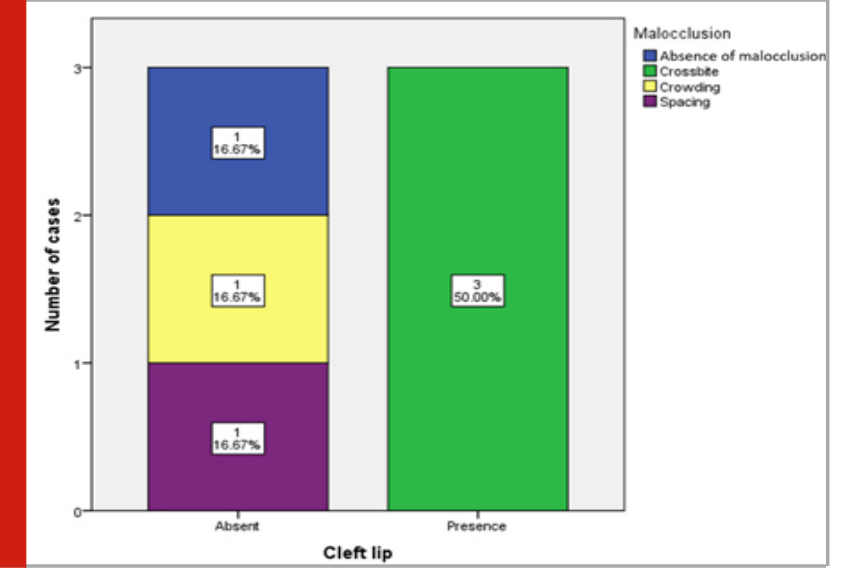

The importance of identifying these malocclusion in children cannot be emphasized enough as they do not only have aesthetic concerns but also function and oral health. (Panchal et al., 2019) This is an added disadvantage for cleft lip patients due to their variation in jaw shape and size as reported in a study. There were no significant differences in gender between groups, though more females were recruited in both the sample groups; 56 percent, as opposed to findings that documented more male predilection for cleft lip and/ or palate. This might be due to the small sample size of this study. The present study data supports that children with cleft palate have a higher incidence of malocclusion compared to the non-cleft palate group. The mean rank for malocclusion in the case group was 12.17 and 24.83 in the control group with a Mann-Whitney test value of 48.00 . A supportive study (Maciel, Costa and Gomide, 2005; Akcam et al., 2008; Vettore and Sousa Campos, 2011; Ramakrishnan and Bhurki, 2018).

In 2011 on 117 subject samples reported that individuals with cleft lip and/or palate had higher incidence and more severe form of malocclusion as compared to non-cleft lip and/or palate. As theorised in a study prior, alteration in the dimensions of the jaw may be a Possible explanation as to why malocclusion is more prevalent in cleft lip and/or palate group. Sometimes, due to the poor oral health condition of cleft patients, the children develop dental caries which leads to loss of tooth structure followed by drifting of teeth eventually ending in malocclusion. The unusual tongue placement/movement which also leads to altered pattern of swallowing or poor swallow reflex has also been theorized as a major factor for malocclusion as the tongue plays an important role in guiding the teeth into occlusion. (Chopra et al., 2014; Vignesh and Sharmin, 2018; Hou, 2020)

Malocclusion like crowding and spacing due to alteration in the dimensions of the jaw, making them relatively larger or smaller as compared to the teeth size, as we know, also supports this fact. The study done by Baek et al. also revealed an affinity between the varying types of orofacial clefts and malocclusion. Hopefully more studies are employed in the future to determine or correlate the types of malocclusion in variation of cleft lip and/or palate groups. As mentioned by Zhou et al., genetic disturbances in the embryonic period, along with genetic interactive pathways could be another explanation as to why malocclusion is more prevalent in cleft lip and/or palate group, as it is already theorised for being a factor that causes cleft lip and/or palate, thus making it a possibility (Baek, 2002; Zhou et al., 2016).

Malocclusion, besides being a major concern by itself, is also a catalytic factor for the development of dental caries due to presence of areas prone for accommodating dental plaque. Our institution is passionate about high quality evidence based research and has excelled in various fields (Ranta, 1986; Subramanyam et al., 2018; Pc et al., 2018; Ramesh et al., 2018; Ezhilarasan et al., 2019; Ramadurai et al., 2019; Sridharan et al., 2019; Vijayashree, 2019; Mathew et al., 2020). We hope this study adds to this rich legacy.

This study will help to provide knowledge for better educating the people, especially the parents of children with cleft, on malocclusion and the need for seeking treatment. Studies like this could aid dentists who are predominantly handling cleft lip and/or individuals, to predict malocclusion that may occur along the course of treatment so that they may be able to prepare themselves or incorporate minor prophylaxis treatment also in the treatment plan for these 
patients which could prove to be cost and time efficient. To procure a more efficient treatment plan, this knowledge could help dentists to achieve an accurate diagnosis (Christabel and Gurunathan, 2015; Packiri et al., 2017).

The limitation of this study was that it is a unicentric study which is limited to only one population visiting the private institute. Besides that, the geographic restrictions and lower external validity were also another drawback of this study. The advantage of this study is that we get to collect reasonable data as it is a case control study, with high internal validity. However, this study can be improved by making it a multicentric study with different parameters to measure which will improvise future studies.

\section{CONCLUSION}

Within the limitations of the present study, the incidence of malocclusion was found to be higher in cleft patients when compared to non-cleft palate patients. Based on the findings of the study, there is a significant difference on malocclusion incidence between cleft palate and non-cleft palate patients.

\section{REFERENCES}

Akcam, M. O. et al. (2008). Evaluation of 3-dimensional tooth crown size in cleft lip and palate patients, American Journal of Orthodontics and Dentofacial Orthopedics, pp. 85-92. doi: 10.1016/j.ajodo.2006.05.048.

Baek, S.-H. (2002). Cleft type and Angle's classification of malocclusion in Korean cleft patients, The European Journal of Orthodontics, pp. 647-653. doi: 10.1093/ ejo/24.6.647.

Chopra, A. et al. (2014). Oral health in 4-6 years children with cleft lip/palate: a case control study, North American journal of medical sciences, 6(6), pp. 266-269.

Christabel, S. L. and Gurunathan, D. (2015). Prevalence of Type of Frenal Attachment and Morphology of Frenum in Children, Chennai, Tamil Nadu, World Journal of Dentistry, pp. 203-207. doi: 10.5005/jp-journals-100151343.

Dhar, V. et al. (2007). Prevalence of gingival diseases, malocclusion and fluorosis in school-going children of rural areas in Udaipur district, Journal of the Indian Society of Pedodontics and Preventive Dentistry, 25(2), pp. 103-105.

Ezhilarasan, D., Apoorva, V. S. and Ashok Vardhan, N. (2019). Syzygium cumini extract induced reactive oxygen species-mediated apoptosis in human oral squamous carcinoma cells, Journal of oral pathology \& medicine: official publication of the International Association of Oral Pathologists and the American Academy of Oral Pathology, 48(2), pp. 115-121.

Gheena, S. and Ezhilarasan, D. (2019). Syringic acid triggers reactive oxygen species-mediated cytotoxicity in HepG2 cells, Human \& experimental toxicology, 38(6), pp. 694-702.

Govindaraju, L. and Gurunathan, D. (2017). Effectiveness of Chewable Tooth Brush in Children-A Prospective Clinical Study, Journal of clinical and diagnostic research: JCDR, 11(3), pp. ZC31-ZC34.

Govindaraju, L., Jeevanandan, G. and Subramanian, E. (2017). Clinical Evaluation of Quality of Obturation and Instrumentation Time using Two Modified Rotary File Systems with Manual Instrumentation in Primary Teeth, Journal of clinical and diagnostic research: JCDR, 11(9), pp. ZC55-ZC58.

Govindaraju, L., Jeevanandan, G. and Subramanian, E. M. G. (2017a). Comparison of quality of obturation and instrumentation time using hand files and two rotary file systems in primary molars: A single-blinded randomized controlled trial, European journal of dentistry, 11(3), pp. 376-379.

Govindaraju, L., Jeevanandan, G. and Subramanian, E. M. G. (2017b). Knowledge and practice of rotary instrumentation in primary teeth among indian dentists: A questionnaire survey, Journal of International Oral Health, 9(2), p. 45.

Gupta, A. et al. (2016). Assessing Angle's malocclusion among cleft lip and/or palate patients in Jammu, Journal of International Society of Preventive \& Community Dentistry, 6(Suppl 1), pp. S23-7.

Gurunathan, D. and Shanmugaavel, A. K. (2016). Dental neglect among children in Chennai, Journal of the Indian Society of Pedodontics and Preventive Dentistry, 34(4), pp. 364-369.

Heliövaara, A. et al. (2021). Scandcleft randomized trials of primary surgery for unilateral cleft lip and palate: comparison of dental arch relationships and dental indices at 5, 8, and 10 years, European journal of orthodontics. doi: 10.1093/ejo/cjab055.

Hou, G. L. (2020). Relationship between Molar Root Trunk Type and Molar Loss in Individuals with Class III Furcation Involvements: A Retrospective Study, Advances in Dentistry \& Oral Health. doi: 10.19080/ adoh.2020.13.555866.

Jain, V. S. et al. (2019). Evaluation of Three-Dimensional Changes in Pharyngeal Airway Following Isolated Lefort One Osteotomy for the Correction of Vertical Maxillary Excess: A Prospective Study, Journal of maxillofacial and oral surgery, 18(1), pp. 139-146.

Jeevanandan, G. (2017). Kedo-S Paediatric Rotary Files for Root Canal Preparation in Primary Teeth - Case Report, Journal of clinical and diagnostic research: JCDR, 11(3), pp. ZR03-ZR05.

Jeevanandan, G. and Govindaraju, L. (2018). Clinical comparison of Kedo-S paediatric rotary files vs manual instrumentation for root canal preparation in primary molars: a double blinded randomised clinical trial, 
European archives of paediatric dentistry: official journal of the European Academy of Paediatric Dentistry, 19(4), pp. 273-278.

Jose, J., Ajitha and Subbaiyan, H. (2020). Different treatment modalities followed by dental practitioners for Ellis class 2 fracture - A questionnaire-based survey, The open dentistry journal, 14(1), pp. 59-65.

Kalaskar, R. et al. (2021). Comparative evaluation of nasal and alveolar changes in complete unilateral cleft lip and palate patients using intraoral and extraoral nasoalveolar molding techniques: randomized controlled trial, Journal of the Korean Association of Oral and Maxillofacial Surgeons, 47(4), pp. 257-268.

Ke, Y. et al. (2019). Photosynthesized gold nanoparticles from Catharanthus roseus induces caspase-mediated apoptosis in cervical cancer cells (HeLa), Artificial cells, nanomedicine, and biotechnology, 47(1), pp. 19381946.

Krishnaswamy, H. et al. (2020). Investigation of air conditioning temperature variation by modifying the structure of passenger car using computational fluid dynamics, Thermal science, 24(1 Part B), pp. 495-498.

Lakshmanan, L. et al. (2020). Assessing the quality of root canal filling and instrumentation time using kedo-s files, reciprocating files and k-files, Brazilian Dental Science, 23(1), p. 7.

Maciel, S. P., Costa, B. and Gomide, M. R. (2005). Difference in the Prevalence of Enamel Alterations Affecting Central Incisors of Children with Complete Unilateral Cleft Lip and Palate, The Cleft PalateCraniofacial Journal, pp. 392-395. doi: 10.1597/02152.1 .

Malli Sureshbabu, N. et al. (2019). Concentrated Growth Factors as an Ingenious Biomaterial in Regeneration of Bony Defects after Periapical Surgery: A Report of Two Cases, Case reports in dentistry, 2019, p. 7046203.

Mathew, M. G. et al. (2020). Evaluation of adhesion of Streptococcus mutans, plaque accumulation on zirconia and stainless steel crowns, and surrounding gingival inflammation in primary, Clinical oral investigations. Available at: https://link.springer.com/article/10.1007/ s00784-020-03204-9.

Mehta, M. et al. (2019). Oligonucleotide therapy: An emerging focus area for drug delivery in chronic inflammatory respiratory diseases, Chemico-biological interactions, 308, pp. 206-215.

Mtaya, M., Brudvik, P. and Astrøm, A. N. (2009). Prevalence of malocclusion and its relationship with socio-demographic factors, dental caries, and oral hygiene in 12- to 14-year-old Tanzanian schoolchildren, European journal of orthodontics, 31(5), pp. 467-476.

Muthukrishnan, S. et al. (2020). Support vector machine for modelling and simulation of heat exchangers, Thermal science, 24(1 Part B), pp. 499-503.

Packiri, S., Gurunathan, D. and Selvarasu, K. (2017). Management of Paediatric Oral Ranula: A Systematic Review, Journal of clinical and diagnostic research: JCDR, 11(9), pp. ZE06-ZE09.

Panchal, V. et al. (2019). Comparison of instrumentation time and obturation quality between hand K-file, H-files, and rotary Kedo-S in root canal treatment of primary teeth: A randomized controlled trial, Journal of the Indian Society of Pedodontics and Preventive Dentistry, 37(1), p. 75.

Pc, J., Marimuthu, T. and Devadoss, P. (2018). Prevalence and measurement of anterior loop of the mandibular canal using CBCT: A cross sectional study, Clinical implant dentistry and related research. Available at: https:// europepmc.org/article/med/29624863.

Ramadurai, N. et al. (2019). Effectiveness of $2 \%$ Articaine as an anesthetic agent in children: randomized controlled trial, Clinical oral investigations, 23(9), pp. 3543-3550.

Ramakrishnan, M. and Bhurki, M. (2018). Fluoride, Fluoridated Toothpaste Efficacy And Its Safety In Children - Review, International Journal of Pharmaceutical Research, 10(04), pp. 109-114.

Ramesh, A. et al. (2018). Comparative estimation of sulfiredoxin levels between chronic periodontitis and healthy patients - A case-control study, Journal of periodontology, 89(10), pp. 1241-1248.

Ranta, R. (1986). A review of tooth formation in children with cleft lip/palate, American Journal of Orthodontics and Dentofacial Orthopedics, pp. 11-18. doi: 10.1016/08895406(86)90022-3.

Ravikumar, D., Jeevanandan, G. and Subramanian, E. M. G. (2017). Evaluation of knowledge among general dentists in treatment of traumatic injuries in primary teeth: A cross-sectional questionnaire study, European journal of dentistry, 11(2), pp. 232-237.

Samuel, M. S. et al. (2019). Efficient removal of Chromium(VI) from aqueous solution using chitosan grafted graphene oxide (CS-GO) nanocomposite , International journal of biological macromolecules, 121, pp. 285-292.

Samuel, S. R., Acharya, S. and Rao, J. C. (2020). School Interventions-based Prevention of Early-Childhood Caries among 3-5-year-old children from very low socioeconomic status: Two-year randomized trial, Journal of public health dentistry, 80(1), pp. 51-60.

Sathish, T. and Karthick, S. (2020). Wear behaviour analysis on aluminium alloy 7050 with reinforced $\mathrm{SiC}$ through taguchi approach, Journal of Japan Research Institute for Advanced Copper-Base Materials and Technologies, 9(3), pp. 3481-3487.

Sharma, P. et al. (2019). Emerging trends in the novel drug delivery approaches for the treatment of lung cancer , Chemico-biological interactions, 309, p. 108720. 
Shivakumar, K., Chandu, G. and Shafiulla, M. (2010). Severity of Malocclusion and Orthodontic Treatment Needs among 12- to 15-Year-Old School Children of Davangere District, Karnataka, India, European journal of dentistry, 4(3), pp. 298-307.

Somasundaram, S. et al. (2015). Fluoride Content of Bottled Drinking Water in Chennai, Tamilnadu, Journal of clinical and diagnostic research: JCDR, 9(10), pp. ZC32-4.

Sridharan, G. et al. (2019). Evaluation of salivary metabolomics in oral leukoplakia and oral squamous cell carcinoma, Journal of oral pathology \& medicine: official publication of the International Association of Oral Pathologists and the American Academy of Oral Pathology, 48(4), pp. 299-306.

Subramanyam, D. et al. (2018). Comparative evaluation of salivary malondialdehyde levels as a marker of lipid peroxidation in early childhood caries, European journal of dentistry, 12(1), pp. 67-70.

Varghese, S. S., Ramesh, A. and Veeraiyan, D. N. (2019). Blended Module-Based Teaching in Biostatistics and Research Methodology: A Retrospective Study with Postgraduate Dental Students, Journal of dental education, 83(4), pp. 445-450.

Venu, H., Raju, V. D. and Subramani, L. (2019). Combined effect of influence of nano additives, combustion chamber geometry and injection timing in a DI diesel engine fuelled with ternary (diesel-biodiesel-ethanol) blends, Energy, 174, pp. 386-406.

Venu, H., Subramani, L. and Raju, V. D. (2019). Emission reduction in a DI diesel engine using exhaust gas recirculation (EGR) of palm biodiesel blended with $\mathrm{TiO} 2$ nano additives, Renewable Energy, 140, pp. 245-263.

Vettore, M. V. and Sousa Campos, A. E. (2011). Malocclusion characteristics of patients with cleft lip and/ or palate, European journal of orthodontics, 33(3), pp. 311-317.

Vignesh, R. and Sharmin, D. (2018). A comparative evaluation between cheiloscopic patterns and canine relationship in primary dentition, Journal of Forensic Dental Sciences, p. 84. doi: 10.4103/jfo.jfds_21_17.

Vignesh, R. et al. (2019). Management of Complicated Crown-Root Fracture by Extra-Oral Fragment Reattachment and Intentional Reimplantation with 2 Years Review, Contemporary clinical dentistry, 10(2), pp. 397-401.

Vijayashree P. J. (2019). In silico validation of the non-antibiotic drugs acetaminophen and ibuprofen as antibacterial agents against red complex pathogens, Journal of periodontology, 90(12), pp. 1441-1448.

Zhou, Z. et al. (2016). Prevalence of and factors affecting malocclusion in primary dentition among children in Xi'an, China, BMC oral health, 16(1), p. 91. 